\title{
Perceptions of fishers and developers on the co-location of offshore wind farms and decapod fisheries in the UK
}

\author{
Tara Hooper*, Matthew Ashley and Melanie Austen
}

Plymouth Marine Laboratory, Prospect Place, The Hoe, Plymouth, PL1 3DH

* Corresponding author.

tel: + 44 (0) 1752 633100; email: tarh@pml.ac.uk

\begin{abstract}
The predicted expansion of the global offshore wind sector is likely to increase conflicts as users of the coastal zone compete for space, and the displacement of fisheries is of particular concern. It is therefore important to explore opportunities that could support the co-existence of offshore wind farms (OWFs) and fishing activity. In addition to ecological evidence on the effects of OWFs on commercially exploited species, the co-location issue requires understanding of the perceptions of fishers and OWF developers on key constraints and opportunities. Interviews were carried out in 2013 with 67 fishers in South Wales and Eastern England and with 11 developers from major energy companies, to discover experiences and opinions on the co-location of OWFs with crab and lobster fisheries. Developers expressed broad support for co-location, perceiving potential benefits to their relationship with fishers and their wider reputation. Fishers had more mixed opinions, with geographical variation, and exhibited a range of risk perception. The lack of reported experience of potting within OWFs was not related to stock concerns but to uncertainty around safety, gear retrieval, insurance and liability. Clear protocols and communication to address these issues are essential if colocation is to be feasible. Scale may also limit the potential benefits to fishers, especially in that large offshore OWFs are likely to be inaccessible to much of the inshore fleet. There remains the potential to enhance the artificial reef effects of OWFs by deploying additional material between the turbines, but options to finance such schemes, and how investment by OWF developers could be offset against compensation paid to displaced fishers, require further investigation.
\end{abstract}

\section{Keywords}

Offshore wind energy; co-location; crab fishing; lobster fishing.

\section{Introduction}

Globally, offshore marine renewable energy exploitation is increasing as a way of reducing carbon emissions and hence climate change impacts. In UK waters alone, over 1,500 offshore wind turbines were operational or in construction at the end of 2014, with a further 2,700 consented or formally submitted for planning approval [1]. Continued expansion of the sector is likely to bring offshore 
wind into conflict with other users of the coastal zone. The displacement of fishing activity by infrastructure developments is a particular concern that has been highlighted within the UK's Marine Policy Statement (MPS) [2], the document providing the framework for the development of Marine Plans for England's coastal and offshore waters. The MPS concludes (p43) that "wherever possible, decision makers should seek to encourage opportunities for co-existence between fishing and other activities." The increased demand for utilisation of marine space and the need to promote sustainable co-existence of users in order to reduce conflicts and maximize economic opportunities is recognised internationally, within, for example, the EU Directive establishing a Framework for Maritime Spatial Planning (2014/89/EU) and the US Government's National Ocean Policy Implementation Plan [3].

The ecological basis for the potential co-location of offshore wind farms (OWFs) and fisheries results from the artificial reef effects generated because OWF infrastructure provides hard substrate habitat, usually in places where it previously did not exist. There is some evidence from ecological surveys that this new habitat already supports populations of commercially important crab species, and rock armour and concrete gravity base foundations could provide habitat for European lobster [4]. This provides encouraging support for the possibility of co-locating OWFs with crab and lobster fisheries. However, before recommendations can be made on the possibilities of co-location, it is important to ascertain whether it will be possible for fishers to take advantage of any increase in crab and lobster stocks, or whether practical constraints will prevent realisation of the opportunity. This research therefore used interviews to examine the opinions of OWF developers and fishers to find out what their experience has been, and their expectations are, of OWF impacts and co-location issues such as access and safety. This addresses a gap in the literature, as previous studies have been dominated by perceptions of the implications for mobile gear, and detailed assessments of practical constraints and opportunities for shellfishers are lacking.

\section{Existing co-location of fishing and energy development}

The exemplar of co-location between capture fisheries and energy infrastructure is off the coast of Louisiana. There are some 4,000 oil and gas platforms in the Gulf of Mexico [5], which have become the focus of recreational fishing in particular, due to the absence of natural reefs in the area [6]. Fishers are prepared to travel over $100 \mathrm{~km}$ per trip to reach the platforms [7], and access the structures at a frequency of approximately six boats per month per platform [8]. The value of the platforms to recreational fishing was a key driver in the establishment of the "Rigs to Reefs" programme [6], and over 330 artificial reefs have now been created in Louisiana waters from decommissioned oil and gas platforms [9]. Commercial rod and line fishing has also been observed at oil and gas platforms, often at distances in excess of $100 \mathrm{~km}$ offshore, although at a frequency of only about $10 \%$ of that for recreational fishing [8]. 
There is less evidence of successful co-location between energy and fisheries in the temperate waters of the North East Atlantic. In some cases, such co-location is not possible: in the UK, vessels are prohibited from entering safety zones extending $500 \mathrm{~m}$ from any point of an offshore oil or gas structure under Section 23 of the Petroleum Act 1987 [10]. Trawlers have been observed to fish in close proximity to OWFs and Norwegian oil platforms, although it is not known whether this is a displacement effect as the boats are unable to fish within the footprint of the infrastructure, or the result of a change in the availability of target species [11,12].

In the absence of empirical evidence of actual fishing behaviour in relation to existing energy infrastructure, the focus of research has been on the concerns of fishing industry with regard to the potential impacts of OWFs (and other marine renewable energy) developments. These studies highlight fishers' concerns about loss of fishing grounds and displacement, safety and gear loss, and inadequate consultation and communication [13-18]. A minority of fishers do perceive the potential opportunities presented by artificial reef effects causing target species to aggregate at OWF foundations, and they are also aware of possible spillover effects of individuals from within a refuge created by the exclusion of fishing from the footprint of the infrastructure [14-16].

\section{Method}

Face-to-face semi-structured interviews were carried out with fishers and representatives of companies developing OWFs (hereafter "developers") between May and December 2013. Fisher interviews took place in North Norfolk/South Lincolnshire (referred to as the "Norfolk" sample), East/North Yorkshire (the "Yorkshire" sample) and South Wales (Figure 1). These sites were selected to obtain a range of opinions that would take account of the variation in the scale of OWF developments and the relative importance of crab and lobster fisheries for different regions of the UK. The central North Sea is a particular focus of OWF development with operational sites near the coasts of North Norfolk/South Lincolnshire and partially constructed, consented and proposed sites within this area and extending north into the coastal and offshore regions of Yorkshire. There are currently no OWFs in the Bristol Channel, although it does contain a leased area that, during the data collection period, was proposed for the Atlantic Array. Crab and lobster fisheries are particularly important in North East England: accounting for over 30\% of landings by weight into Scarborough and Grimsby in 2011 compared to $13 \%$ of landings into the Bristol Channel ports of Milford Haven, Saundersfoot and Ilfracombe [19]. The Norfolk fisheries are again different with shellfish accounting for over $90 \%$ of landings into Great Yarmouth and Lowestoft, but with molluses dominating and decapod species accounting for only a very small proportion of the total [19; MMO unpublished data]. 
The questionnaire forming the basis for interviews with developers had four main sections: i) the exclusion of fisheries either entirely or partially from OWFs; ii) access and licensing of crab/lobster fisheries within OWFs; iii) potential benefits and financing of strategies to enhance artificial reef effects; and iv) experiences of fishing inside existing OWFs. The interviews with fishers included, similarly, questions on access, licensing and the financing of artificial reef enhancement schemes, as well as on actual and expected impacts of OWFs on fishing activities, and the perceived benefit or harm OWFs could do to crab/lobster fisheries. Crab/lobster fishers were asked about current practices, as a means of understanding existing operational and safety issues that may affect their ability to exploit any benefits from OWFs.

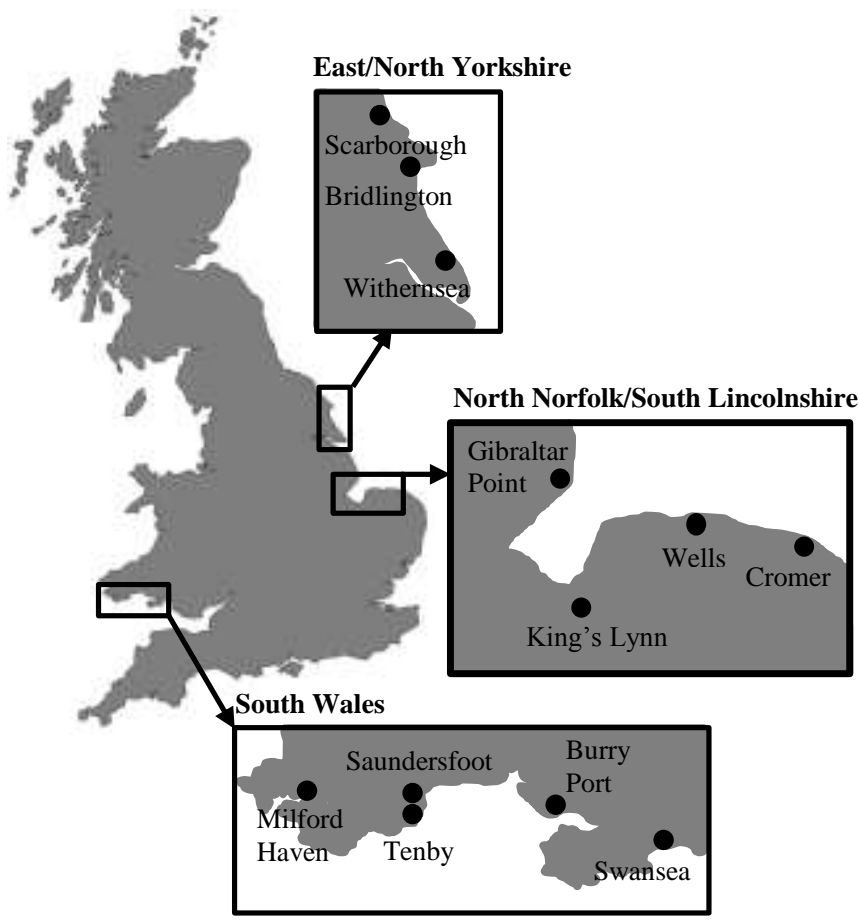

Figure 1. The sites at which fishers were interviewed

\section{Results}

\subsection{Sample groups}

Completed questionnaires were received from eleven offshore wind developers, at least two of which represented the collective views of multiple individuals. Interviews were carried out with 67 fishers, most of whom were full-time fishers in the under $10 \mathrm{~m}$ fleet with, on average, over 20 years' experience (Table 1). The crab/lobster fishery was a particularly important source of income for Yorkshire fishers, although Norfolk fishers had the greatest financial dependence on fishing in general. 
Table 1. Descriptive statistics for the fishers from the different geographical areas

\begin{tabular}{|c|c|c|c|c|c|c|c|c|c|}
\hline Site & $\begin{array}{c}\text { Total } \\
\text { sample } \\
\text { size }\end{array}$ & $\begin{array}{c}\text { Number } \\
\text { of } \\
\text { potters }\end{array}$ & $\begin{array}{c}\text { Average } \\
\text { age } \\
\text { group }\end{array}$ & $\begin{array}{c}\text { Average } \\
\text { years } \\
\text { fishing }\end{array}$ & $\begin{array}{l}\text { Average } \\
\text { fishing } \\
\text { days per } \\
\text { year }\end{array}$ & $\begin{array}{l}\text { Full } \\
\text { time } \\
\text { fishers } \\
(\%)\end{array}$ & $\begin{array}{c}\text { Under } \\
10 \mathrm{~m} \\
\text { vessels } \\
(\%)\end{array}$ & $\begin{array}{l}\text { Income } \\
\text { solely } \\
\text { from } \\
\text { fishing } \\
(\%)\end{array}$ & $\begin{array}{c}\text { Main } \\
\text { fishing } \\
\text { income } \\
\text { from crab/ } \\
\text { lobster }(\%)\end{array}$ \\
\hline South Wales & 26 & 14 & $45-54$ & 27 & 139 & 81 & 92 & 63 & 29 \\
\hline Norfolk & 22 & 14 & $55-64$ & 32 & 160 & 77 & 68 & 80 & 57 \\
\hline Yorkshire & 19 & 18 & $45-54$ & 23 & 153 & 68 & 58 & 58 & 95 \\
\hline All sites & 67 & 46 & $45-54$ & 27 & 150 & 76 & 75 & 67 & 58 \\
\hline
\end{tabular}

In South Wales and Norfolk all fishers approached were willing to be interviewed, but in Yorkshire the response rate was $23 \%$, due to a large number of refusals from fishers in Bridlington. The reasons expressed included: i) there being no benefit to the fisher in doing so; ii) concerns over low literacy levels and the length of the survey; iii) 'survey fatigue', as a results of having been approached by multiple researchers while having seen no results on the ground; and iv) a general feeling that fishers' opinions on OWF development were not taken into account during consenting.

\subsection{Fishers' perceptions of the effect of OWFs on crab and lobster fisheries}

When asked about the likely benefit of, or harm to, crab/lobster fisheries that would be caused by OWFs, a high proportion of respondents either did not know, did not answer, or neither agreed nor disagreed with the statements (Figure 2). There was some evidence that fishers from South Wales, where no OWFs had yet been constructed, had a more positive attitude to OWFs, as a higher percentage agreed that OWFs could benefit, and disagreed that OWFs could harm, crab/lobster fisheries. There was also the suggestion that fishers from Yorkshire had more emphatic opinions. Where the aggregated rate of positive or negative responses was similar to that for Norfolk, a higher percentage of the Yorkshire fishers chose the "strongly" agree or disagree option.

\subsection{Access to $O W F s$}

The maximum water depth in which potters were prepared to set gear ranged from $15 \mathrm{~m}$ to $90 \mathrm{~m}$ (median 40m), and the maximum distance they were prepared to travel offshore ranged from $8 \mathrm{~km}$ to $165 \mathrm{~km}$ (median $25 \mathrm{~km}$ ). A sample of $43 \mathrm{UK}$ OWFs shows that turbines have been, or will be, constructed in water depths ranging from $4 \mathrm{~m}$ to $66 \mathrm{~m}$ and from $2 \mathrm{~km}$ to $149 \mathrm{~km}$ offshore [1].

\subsection{Effects of OWFs on fishing activities}

The extent to which fishers had been affected by OWFs varied (Table 2). Within the Yorkshire sample, no Scarborough fisher had grounds within five miles of an OWF or cable route, and their fishing activities had been unaffected by OWFs. This was in contrast to their counterparts from Bridlington and Withernsea, and also to the Norfolk sample. Across all sites, fishers had similar expectations of the likelihood of additional OWFs affecting their fishing activities. 
a) Offshore wind farms could benefit crab fisheries because they create new habitat and support prey

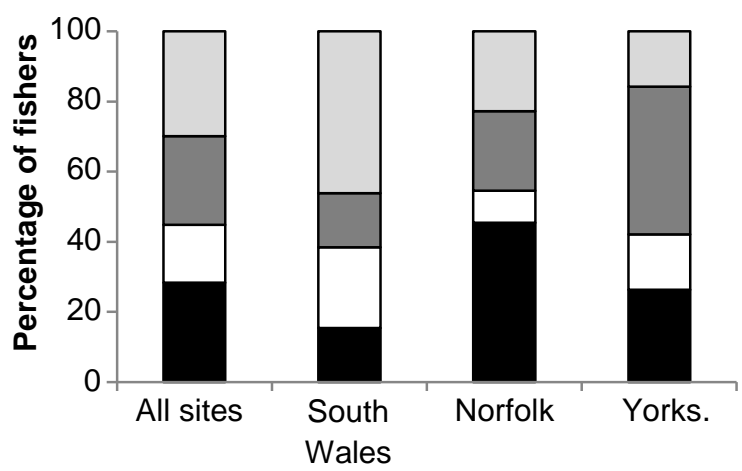

Sampling location b) Offshore wind farms could benefit lobster fisheries because they create new habitat and support prey

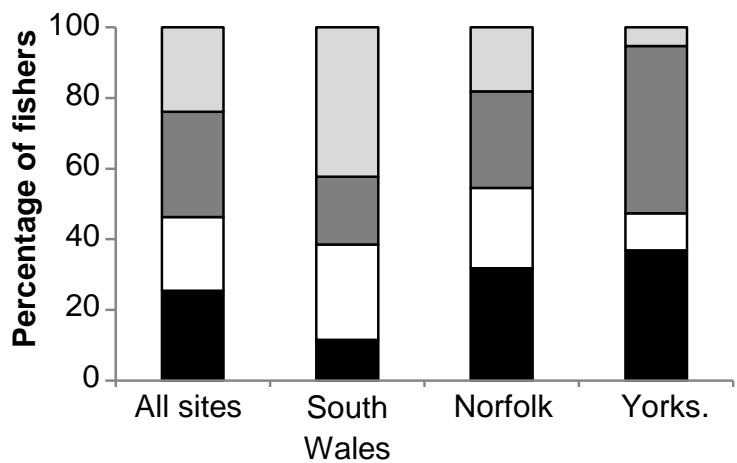

Sampling location

Disagree $\square$ Agree $\square$ Neutral $\square$ Don't know/didn't answer

c) Offshore wind farms will harm crab fisheries because impacts on the seabed will threaten stocks

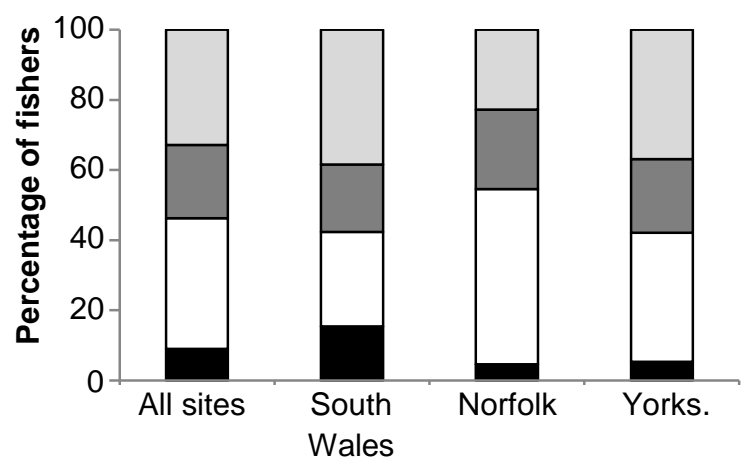

Sampling location d) Offshore wind farms will harm lobster fisheries because impacts on the seabed will threaten stocks
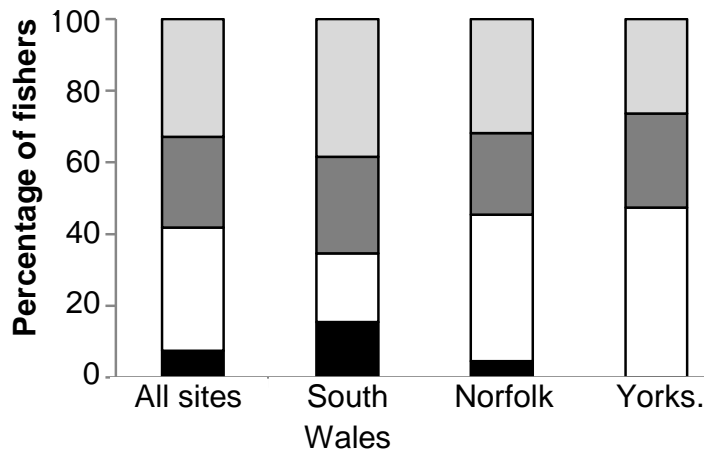

Sampling location

Figure 2. The percentage of fishers who agree or disagree with statements that OWFs will a) benefit crab fisheries; b) benefit lobster fisheries; c) harm crab fisheries; d) harm lobster fisheries

Table 2. The percentage of fishers from each sample site who have been, and expect to be, affected by OWFs

\begin{tabular}{lrrrr}
\hline & $\begin{array}{c}\text { South } \\
\text { Wales }\end{array}$ & Norfolk & Yorkshire & All sites \\
\hline $\begin{array}{l}\text { At least one operational or partially constructed OWF within } \\
\text { one mile of fishing grounds }\end{array}$ & $\mathrm{n} / \mathrm{a}$ & 95 & 44 & 72 \\
All four operational OWFs within one mile of fishing grounds & $\mathrm{n} / \mathrm{a}$ & 48 & 11 & 31 \\
Fishing activities have been affected by existing OWFs & $\mathrm{n} / \mathrm{a}$ & 95 & 38 & 70 \\
At least one proposed OWF within one mile of fishing grounds & 19 & 76 & 50 & 46 \\
Proposed OWFs are expected to affect fishing activities & 77 & 85 & 69 & 77 \\
\hline
\end{tabular}


The main effect of OWFs on fishing was loss of ground. Other reported impacts were the loss or movement of gear; disruption to fishing effort caused by the need to move gear to make way for OWF maintenance; and disturbance caused by construction activities (in particular a mass movement of crabs away from fishing grounds in Norfolk). Increased siltation was reported as an important impact by Norfolk fishers. The loss of fishing grounds was also the main impact that fishers were expecting as a result of the construction of additional OWFs. There was an almost equal level of concern (particularly within South Wales) about the displacement of other fishers (particularly those using mobile gear) from OWF sites onto traditional potting grounds.

It seems unlikely that the effects of displacement would include a significant number of fishers changing from mobile gear to crab/lobster potting. Twenty one respondents did not currently fish for crab/lobster. Even though $81 \%$ of these expected to lose fishing grounds if proposed OWFs were built, less than $20 \%$ (just 4 fishers) would consider changing to crab/lobster fishing if it was demonstrated that the OWFs supported good stocks of the crustaceans. Fishers stated that the main reason for their low interest in changing gear type was that they lacked the necessary shellfish licence. The current high levels of potting and the saturated market were also factors.

More than half of the fishers interviewed expected to receive financial compensation for disruption of fishing activity if new OWFs were built, although 36\% either did not know or did not answer the question on that issue. Additional comments made by fishers suggested that they did not all feel that the compensation process was equitable: those who did not currently fish in proposed OWF areas but would be affected by those displaced from the OWF sites did not feel they would be adequately considered.

Developers also reported that their activities had been impacted by fishers. Half of developers with operational or largely constructed OWFs reported negative experiences with fishers within their sites. One of these problems concerned fishers "attempting to tie on to structures, seeking to harvest mussels". Other respondents reported "deliberately obstructive behaviour" such as gear being left in areas in which the company had advised it would be working, and "purposely hindering the activities". One developer also perceived the issue of compensation as creating particular problems.

\subsection{Current levels of fishing within OWFs}

Over $60 \%$ of developers believed that crab/lobster fishing should be permitted within OWFs. Respondents commented that co-location "seems logical if managed properly", that "in principle we should be encouraging symbiotic relationships between developers and fishermen" and that there is "no reason why can't co-exist if systems to ensure turbines are safe" (sic). Eighty percent of 
respondents also agreed or strongly agreed that establishing an OWF as a no-take zone in which no fishing at all was permitted was likely to increase conflict with the fishing community.

However, developers employed by companies with operational or largely constructed OWFs (55\% of respondents) were generally unfamiliar with the fishing activities that were currently being carried out at their site. Only two respondents could provide information, and reported crab/lobster potting occurring "sometimes" or "frequently" within their OWFs. Rod and line fishing, the only other fishing activity that occurred in both OWFs, also took place "sometimes" at each site. Other shellfishing, and pelagic and demersal trawling were reported from one OWF. Only three fishers reported having set pots within an OWF, although $44 \%$ of those with operational/partially constructed OWFs on their fishing grounds reported setting pots around the outside of an OWF (usually also potting close to the cable).

\subsection{Barriers to fishing within OWFs}

Nearly $90 \%$ of those potters who would not set gear near OWF turbines gave responses on the theme of safety and gear loss. There were concerns that bad weather or strong tides would lead to pots becoming entangled with OWF infrastructure and that difficult sea conditions would bring the risk of boats colliding with turbines while attempting to retrieve gear. One third of the fishers in Yorkshire were concerned about the validity of their insurance if fishing within OWFs, and a minority (11\%) of fishers were also unsure whether they were permitted to fish within OWFs.

Developers expressed similar concerns about the deployment of gear within OWFs, particularly the possibility of snagging of, and damage to, cables; interference with maintenance operations; and liability issues if pots became entangled. More than half advocated that pots should be deployed at a minimum distance of at least $100 \mathrm{~m}$ from turbine infrastructure. The smallest safe minimum distance proposed was $25 \mathrm{~m}$, while the largest was $500 \mathrm{~m}$. Fishers had a similar opinion on minimum safe distances: the median distance from a turbine that potters would set their gear was $100 \mathrm{~m}$ (range $1 \mathrm{~m}$ to 2000m).

\subsection{Comparison with current practices}

The minimum safe distances proposed are conservative compared to current fishing practices related to other natural and artificial structures. Nearly $90 \%$ of the potters interviewed set their gear within $50 \mathrm{~m}$ of a reef, wreck or similar structure. All but one potter from Norfolk and more than half of those from Yorkshire would set pots right on such structures. Conversely, only $42 \%$ of all potters interviewed would set their gear within 50m of an OWF turbine. Reported reasons were again collision risk and uncertainty as to the validity of their insurance, but also the inability to use 
grappling hooks to search for lost gear (as they would in the open sea) due to the risk of snagging cables. No fishers reported any actual incidents of entanglement with OWF infrastructure. The main reason for current gear loss in general (reported by $70 \%$ of potters across all sites) was marine traffic towing away pots: a bigger impact even than bad weather $(67 \%)$.

The need to maintain a minimum safe distance may reduce the benefit that could be obtained from artificial reef effects. On average, fishers felt that the maximum distance from turbines they could set gear and still benefit from the artificial reef effects was $50 \mathrm{~m}$ (range $0 \mathrm{~m}$ to $400 \mathrm{~m}$ ).

\subsection{Licensing and investment}

Seventy percent of developers expressed a preference for crab/lobster fisheries within OWFs to be licensed. The most common reason given was that this would allow them know who was operating within the OWF (helping to address issues of accountability and liability), and would increase opportunities for engagement and co-operation. Only $20 \%$ of fishers believed that Several or Regulating Orders would be a workable means of licensing fisheries within OWFs, although $46 \%$ of respondents did not know or did not answer the question. The principal objection to licencing (expressed by $44 \%$ of respondents) was that it would restrict traditional open access rights. Other reasons given were difficulties in policing, a reiteration of safety and access issues, and potential future problems in transferring licences from one fisher to another. Fishers from Norfolk suggested that a community managed territorial rights fishery would be a better model.

Fishers were also asked if they would consider investing to enhance the artificial reef potential of the site: $28 \%$ would consider doing so, if given a licence to pot within OWFs. Again, many fishers were unsure: $40 \%$ did not know or did not answer the question. Those who would not invest felt that the materials would be too expensive and the effects of the OWFs were too uncertain.

Developers were divided on whether there could be benefits to their companies from actively enhancing the artificial reef effects of OWFs in order to better attract crab/lobster and so support fisheries. Half of respondents agreed that there would be benefits, $30 \%$ disagreed and $20 \%$ did not know. Possible enhancement of the company's reputation was the potential benefit most commonly proposed by developers, and increased co-operation with fishing groups was also mentioned. It was also suggested that enhancing artificial reef effects would only provide real benefit to companies if it helped the consenting process. Only one developer believed that securing these benefits would be worth his/her company incurring some extra cost, with others commenting that OWF costs had to be minimised due to pressure to keep down energy prices. One further respondent did suggest that 
investment in enhancing artificial reef effects could be worthwhile if it could be offset against fisher compensation costs.

\subsection{General comments}

In general comments unprompted by specific questions, developers stated that they were seeking a relationship with fishers that is "based upon mutual respect and within a suitable framework or control", which needs "mutual understanding" and requires "early and thorough engagement". One respondent also noted that starting a dialogue could mean "positive outcomes might be more apparent". These views were echoed by some fishers who realised the need for a compromise between the two industries, suggesting the need for "better co-operation between fishing organisations and OWF developers from the outset" and that "wind farm companies should work with fishermen to continue fishing within wind farms".

However, fishers used the opportunity for unstructured comments to reiterate their concerns about the effects of noise on marine life and the displacement of other fishers into their grounds. They also suggested a need for more research into the implications of electromagnetic fields and the effects of OWFs on the different lifestages of commercial shellfish. Fishers also suggested that the aquaculture of mussels, oysters, and salmon might be a better option within OWFs, particularly if the cages could be lifted off the seabed to reduce siltation issues. On co-location specifically, $16 \%$ of fishers (all but one of whom were from South Wales) expressed positive comments about the potential, while $26 \%$ expressed negative opinions: fishers from Yorkshire felt that it would not work because of the damage that would be done to the habitats by the OWFs, while those from South Wales and Norfolk were concerned that fisheries within OWFs would be unsafe or uneconomical.

\section{Discussion}

\subsection{The potential for co-location}

The responses received from developers indicate broad support for the possibility of crab and lobster fisheries occurring within their sites, as they perceive potential benefits in improving their relationship with the fishing community and their wider reputation. This supports previous evidence of a desire from developers to encourage co-location [20]. Fishers have a much more diverse range of views on the desirability and practicality of such co-location. While previous studies have reported suggestions from fishers that OWFs have the potential to enhance crab and lobster fishing [13,21], in this study fishers report that disturbance caused during construction or local environmental changes may prevent these benefits being realised. This study also provided evidence that potting nonetheless occurs within and around OWFs. 
Reasons given for a reluctance to set gear within OWFs were not related to stock effects, but to safety, legal and insurance issues, which reflect opinions expressed in other studies [13, 14, 22]. Developers also raised safety and liability concerns. Fishers appear to be more willing to target, and to set gear very close to, natural rocky reefs and other artificial structures such wrecks than they are OWFs. This may be because collision risk is greater as the OWF structure emerges above the surface. There is a spectrum of risk perception amongst fishers, which echoes other studies where some fishers have suggested that "Marine renewable energy devices were unlikely to be any different from other 'fasteners' on the seabed such as rocks" [14].

Effective co-location requires appropriate legal and insurance frameworks to be put in place, and to ensure that these are clearly communicated to the affected fishing community. UK legislation for submarine communications cables is specific on issues such as responsibility for damage and the ability to claim compensation, which are not currently clearly defined in the offshore energy sector [23]. Local conditions will influence safety issues, and so decisions on what is safe and practicable need to be made on an individual, as opposed to generic, basis [24].

\subsection{Gear loss and retrieval}

Gear loss is of particular concern to fishers. Although OWFs may reduce shipping traffic in the area (the primary cause of gear loss reported in this study), there remains the potential for gear to be displaced by OWF maintenance vessels. Fishers are also unsure of the exact location of particular hazards within an OWF, including the key service corridors used during maintenance [22]. Up-to-date accessible mapping of these areas has therefore been suggested, ideally through the existing Seafish Kingfisher information service [22, 23, 25].

Retrieval of lost gear is a related issue, as grappling to snag lost pot strings is perceived to be incompatible with the presence of OWF infrastructure. Even where cables are buried, the trenches created and any backfilling process may increase entanglement risk [21]. Gear adaptations to allow operation within OWFs are possible, such as “snag-proofing' devices" [14], reducing pot string length [26] and floating recovery lines and markers (e.g. US patent 10/237,591). Cooperation between fishers and the OWF industry is key to effective gear recovery, and examples do exist of arrangements made for maintenance vessels to return lost static gear [23, 26]. Again, guidelines for best practice are important, and protocols for reporting fouling and claiming compensation are described in existing guidance for liaison between fishers and the OWF industry [25]. 


\subsection{Scale and access issues}

Artificial reef effects are spatially limited and so exclusion zones around OWF infrastructure may mean that fishers cannot get close enough to the turbines to benefit. UK Electricity regulations (SI No 2007/1948) define a "standard safety zone" of 500m during construction, major maintenance and decommissioning, and 50m during operation, although these are not automatically put in place and do not apply to cables. It has been reported that very few applicants actually seek permission for operational safety zones [27]. Even where safety zones of 50m are established, fishers report that they could still benefit from artificial reef effects at this distance. Observational field studies suggest that artificial reef effects are negligible about 20m from OWF foundations [28, 29], but fishers report that crabs and lobster will travel some distance from reefs when lured by bait.

The issue of scale is also a possible limitation on the potential benefits. Small boats tend to work at least 50 pots, while offshore vessels over $15 \mathrm{~m}$ in length can fish up to 4,000 pots [30]. OWF arrays can occupy a large area of seabed, but the footprint of the foundations, and hence the artificial reef effects, cover a very small fraction of that total site. There have been three leasing rounds (Round 1 to Round 3) in which the Crown Estate has made areas available for OWF development, with Round 1 comprising the earliest and smallest sites. A typical Round 1 site has 30 turbines or less, and the Round 2 sites in operation at the end of 2014 averaged about 100 turbines. As yet, there has been insufficient research, or reported fishing experience, to adequately determine the likely catch from within an OWF and hence the scale of fishery that could be supported. Increases in technology may result in fewer, larger turbines, thus increasing the footprint of each device but reducing that of the OWF as a whole [31], which will also have implications for the size of fishery that could be sustained.

The potential for Round 3 OWFs to sustain profitable fisheries is perhaps greater, due to the larger number of turbines, but these will be of limited benefit to inshore fishers, who tend not to travel far enough offshore or to fish in the likely depths in which Round 3 turbines will be situated. All Round 1 OWFs are in a water depth of $20 \mathrm{~m}$ or less and are within $20 \mathrm{~km}$ from shore, but these developments comprise only 359 turbines in total [1]. For the progressively later and larger leasing zones, only $61 \%$ of Round 2 and $51 \%$ of Round 3 turbines consented or in formal planning at the end of 2014 will be within $30 \mathrm{~km}$ of shore [1], suggesting they may be inaccessible to a significant proportion of inshore fishers. There was some evidence that, as would be expected, those with vessels over $10 \mathrm{~m}$ in length are prepared to travel greater distances. The over $10 \mathrm{~m}$ fleet was under-represented in this study $(25 \%$ of the sample), and it is likely that a higher proportion of these fishers would be able to access OWFs that are further offshore and in deeper water. 


\subsection{Enhancing artificial reef effects}

Augmenting the artificial reef effects of OWF foundations by placing additional material between the turbines has been suggested by fishers as a means of improving economic benefits and safety, with the costs met by developers and offset against compensation [32]. Developers feel under pressure to keep costs down, particularly due to the unpopularity of rising energy bills, and thus report unwillingness to invest in such schemes. However, they would be more likely to do so if compensation costs were reduced correspondingly, and if a willingness to undertake such actions improved the likelihood of development consent being obtained. Within its Marine Plan process, the Marine Management Organisation (MMO) has expressed broad encouragement of co-location and co-existence opportunities, and has developed policies accordingly [33]. Mitigation, as opposed to compensation, schemes may also lever additional funding from external sources [21].

Any option other than compensation may be perceived as benefiting some fishers to the detriment of others [21]. This is perhaps particularly the case with augmenting artificial reef effects, which (unless additional spillover benefits could be demonstrated) would only support crab and lobster fishers, rather than any trawlers displaced from the site. There is no evidence that displaced fishers would change their fishing practices in order to benefit from increased crab and lobster stocks: this study supports earlier findings [13] that cost, licencing, and skill sets are significant barriers to this. Displacement remains a key issue for fishers [13-15, 17, 34]. Enhancing conditions within the OWFs for crab and lobster potters, and thus allowing them to utilise the area profitably, could reduce pressure on grounds outside, mitigating displacement impacts.

\subsection{Management and alternative options}

In terms of managing any crab or lobster fisheries that took place within their OWFs, developers have a clear preference for licensing, so that they know who is navigating and setting gear within their sites. Fishers generally oppose such licensing, arguing that it goes against traditional fishing practice and would be unworkable. Improved relationships between developers and the local fishing community would perhaps address this issue better than licensing, although the availability of exclusive licences has the potential to encourage fishers also to invest in the development of artificial reef materials to augment the fishery.

This study demonstrates resistance within the fishing community to the co-location of crab and lobster fishers with OWFs, so alternative (or potentially complementary) strategies should also be explored. There has been considerable interest in the potential for aquaculture within OWFs, although this has been mainly for shellfish and seaweed [e.g. 35-38], with less attention paid to possibilities of, for 
example, fish cages [39]. Users have also suggested that there is also the potential to co-locate recreational angling, scuba diving and snorkelling activities within OWFs [13, 40, 41].

\section{Conclusions}

There do not appear to be technical issues that would universally preclude the establishment of crab or lobster fisheries within OWFs. However, co-location is unlikely to be a universal panacea, as there are site-specific attitudes and issues, with differences between fishing communities in their support for co-location, and varying levels of risk perception. This study supports previous work in demonstrating that, while fishers fear or have observed some ecological change as a result of OWF development, the primary barriers to co-location are related to safety, potential gear loss or infrastructure damage, and a lack of trust between the fishing community and developers.

Co-location is more likely to be beneficial in areas where crab and lobster habitat is limited, but local conditions, in terms of environmental change brought about by the OWF as well as safety issues, also need to be taken into account. The establishment of successful co-location would be supported by early engagement and community management, and clear protocols for permissions, insurance, liability and gear retrieval are essential. Pilot studies are required, to support development of these protocols and to determine likely catches. A detailed examination of the costs and benefits of developer investment in enhancing artificial reef effects as part of a compensation package should also be undertaken. Such augmentation schemes are likely to be of particular benefit to inshore fishers, who may be unable to access the larger Round 3 OWFs. Other potential co-location activities, of OWFs with aquaculture and recreation, should also be explored further.

\section{Acknowledgements}

This research formed part of the programme of the UK Energy Research Centre and was supported by the UK Research Councils under Natural Environment Research Council award NE/G007748/1.

\section{References}

[1] 4COffshore (2014), 'Global offshore wind farms database', available at http://www.4coffshore.com/windfarms/ (accessed 05 December 2014).

[2] HM Government. 2011. UK Marine Policy Statement. HM Government; Northern Ireland Executive; Scottish Government; Welsh Assembly Government. March 2011 London: The Stationery Office

[3] National Ocean Council. 2013. National Ocean Policy Implementation Plan April 2013. https://www.whitehouse.gov/sites/default/files/national_ocean_policy_implementation_plan.pd f Accessed 18 June 2015

[4] Hooper T. and Austen M. 2014. The co-location of offshore windfarms and decapod fisheries in the UK: Constraints and opportunities. Marine Policy 43: 295-300 
[5] NOAA. (2013). Oil and Gas Exploration. Ocean Explorer. National Oceanic and Atmospheric Administration http://oceanexplorer.noaa.gov/explorations/06mexico/background/oil/oil.html Accessed 15 June 2015

[6] Stanley, D. R., \& Wilson, C. A. (1989). Utilization of offshore platforms by recreational fishermen and scuba divers off the Louisiana coast. Bulletin of Marine Science, 44(2), 767-776.

[7] Gordon, W. R. Jr. (1993). Travel characteristics of marine anglers using oil and gas platforms in the central Gulf of Mexico. Marine Fisheries Review, 55(1), 25-31.

[8] Ditton, R. B., \& Auyong, J. (1984). Fishing offshore platforms central Gulf of Mexico: an analysis of recreational and commercial fishing use at 164 major offshore petroleum structures. Government Reports, Announcements and Index, National Technical Information Service (NTIS), US Department of Commerce, 84(21).

[9] LDWF. (2013). Louisiana Department of Wildlife \& Fisheries 2012-2013 Annual Report. http://www.wlf.louisiana.gov/sites/default/files/pdf/publication/37594-2012-2013-annualreport/2012-2013_annual_report_low-res1.pdf Accessed 18 June 2015

[10] HSE. (2008). Safety zones around oil and gas installations in waters around the UK. Health and Safety Executive www.hse.gov.uk/pubns/indg189.pdf. Accessed 19 June 2015

[11] Osmundsen, P., \& Tveterås, R. (2003). Decommissioning of petroleum installations - major policy issues. Energy policy, 31(15), 1579-1588.

[12] Vandendriessche, S., Hostens, K., Courtens, W., \& Stienen, E. (2013). Fisheries activities change in the vicinity of offshore wind farms. 2013). Environmental Impacts of Offshore Wind Farms in the Belgian part of the North Sea: Learning from the Past to Optimise Future Monitoring Programmes, 81-85.

[13] Mackinson S, Curtis H, Brown R, McTaggart K, Taylor N, Neville S, et al. 2006. A report on the perceptions of the fishing industry into the potential socio-economic impacts of offshore wind energy developments on their work patterns and income. Science Series Technical Report 133. Lowestoft: CEFAS; 60 pp.

[14] Alexander K.A., Potts T. and Wilding T.A. 2013a. Marine renewable energy and Scottish west coast fishers: Exploring impacts, opportunities and potential mitigation. Ocean and Coastal Management 75: 1-10

[15] Alexander K.A., Wilding T.A. and Heymans J.J. 2013b. Attitudes of Scottish fishers towards marine renewable energy. Marine Policy 37: 239-244

[16] Reilly, K., O'Hagan, A. M., \& Dalton, G. (2015). Attitudes and perceptions of fishermen on the island of Ireland towards the development of marine renewable energy projects. Marine Policy, $58,88-97$.

[17] de Groot J., Campbell M., Ashley M., and Rodwell L. 2014. Investigating the co-existence of fisheries and offshore renewable energy in the UK: Identification of a mitigation agenda for fishing effort displacement. Ocean and Coastal Management 102: 7-18.

[18] O'Keeffe, A., \& Haggett, C. (2012). An investigation into the potential barriers facing the development of offshore wind energy in Scotland: Case study-Firth of Forth offshore wind farm. Renewable and Sustainable Energy Reviews, 16(6), 3711-3721.

[19] MMO. 2012. UK Sea Fisheries Statistics 2011. Tables from the publication. 3.14a Landings into major ports in England by UK vessels: 2011; 3.14b Landings into major ports in Wales by UK vessels: 2011. http://www.marinemanagement.org.uk/fisheries/statistics/annual2011.htm Accessed 23 August 2013. 
[20] MMO. (2012b) Marine Planning Workshops: Options. 3 to 4 July 2012. Norwich and Hull. http://webarchive.nationalarchives.gov.uk/20140108121958/http://www.marinemanagement.or g.uk/marineplanning/areas/documents/east_options_workshops.pdf Accessed 19 June 2015

[21] Blyth-Skyrme R.E. 2010. Options and opportunities for marine fisheries mitigation associated with windfarms. Final report for Collaborative Offshore Wind Research Into the Environment contract FISHMITIG09. COWRIE Ltd, London. 125pp.

[22] Rodwell, L.D., De Groot, J.R., Ashley, M., Campbell, M. and Linley, A., 2013. Fisheries and Marine Renewable Energy Interactions: Assessment and Mitigation: a Final Report on the Expert Workshop for the Marine Renewable Energy Knowledge Exchange Programme (MREKEP), York, April 17-18, p. 33.

[23] Red Penguin Associates Ltd. 2012. Submarine Cables and Offshore Energy Installations Proximity Study Report. The Crown Estate. 100pp

[24] Johnson M.L. and Rodmell D.P. 2009. Fisheries, the environment and offshore wind farms: Location, location, location. Food Ethics 4(1): 23-24

[25] FLOWW. 2014. Best Practice Guidance for Offshore Renewables Developments: Recommendations for Fisheries Liaison. Fishing Liaison with Offshore Wind and Wet Renewables Group. January 2014.

[26] MMO. 2013. Potential for co-location of activities in marine plan areas. A report produced for the Marine Management Organisation, pp 98. MMO Project No: 1010.

[27] DECC. 2011. Applying for safety zones around offshore renewable energy installations. Guidance notes. November 2011 (revised). Department for Energy and Climate Change. 19pp.

[28] Wilhelmsson D, Malm T, and Öhman M.C. 2006. The influence of offshore windpower on demersal fish. ICES Journal of Marine Science 63: 775-784

[29] Andersson M. H. and Öhman M. C. 2010. Fish and sessile assemblages associated with windturbine constructions in the Baltic Sea. Marine and Freshwater Research 61(6): 642-650.

[30] Nautilus Consultants Ltd. 2009. Final Report: Future Management of Brown Crab in UK and Ireland. Prepared for the UK and ROI Brown Crab Working Group. 102pp

[31] Wilson J. C., Elliott M., Cutts N. D., Mander L., Mendão V., Perez-Dominguez R., and Phelps A. 2010. Coastal and offshore wind energy generation: is it environmentally benign? Energies 3(7): 1383-1422.

[32] Ashley, M. (2014). The implications of co-locating marine protected areas around offshore wind farms. PhD Thesis. University of Plymouth/Plymouth Marine Laboratory

[33] HM Government. 2014. East Inshore and East Offshore Marine Plans. April 2014. Department for Environment, Food and Rural Affairs, London. 191pp

[34] Gray T., Haggett C., and Bell D. 2005. Offshore wind farms and commercial fisheries in the UK: A study in Stakeholder Consultation. Ethics, Place and Environment: A Journal of Philosophy and Geography: 8(2): 127-140

[35] Shellfish Association of Great Britain. 2012. EFF Project - Shellfish Aq uaculture in Welsh Offshore Wind Farms - Co-location Potential. Scoping Meeting Report. 18pp.

[36] Buck B.H., Ebeling M.W., and Michler-Cieluch T. 2010. Mussel cultivation as a co-use in offshore wind farms: potential and economic feasibility. Aquaculture Economics and Management 14(4):255-81.

[37] Michler-Cieluch T and Krause G. 2008. Perceived concerns and possible management strategies for governing 'wind farm-mariculture integration'. Marine Policy 32:1013-22. 
[38] Benassai G., Mariani P., Stenberg C. and Christoffersen M. 2014. A Sustainability Index of potential co-location of offshore wind farms and open water aquaculture. Ocean \& Coastal Management 95: 213-218.

[39] Mee L. 2006. Complementary benefits of alternative energy: suitability of offshore wind farms as aquaculture sites. inshore fisheries and aquaculture technology innovation and development. SEAFISH—Project Ref. 10517; 36 pp.

[40] Kermagoret C., Levrel H. and Carlier A. 2014. The Impact and Compensation of Offshore Wind Farm Development: Analysing the Institutional Discourse from a French Case Study. Scottish Geographical Journal 130(3) SI: 188-206

[41] Westerberg V., Jacobsen J.B. and Lifran R. 2013. The case for offshore wind farms, artificial reefs and sustainable tourism in the French Mediterranean. Tourism Management 34: 172-183. 